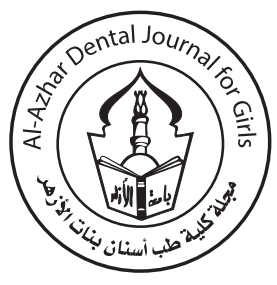

\title{
Effect of Medical History on Different Treatment Modalities in Children Treated under General Anesthesia: A Retrospective Study
}

\author{
Heba M. Elkhodary ${ }^{1^{*}}$
}

Codex : 20/22.01

azhardentj@azhar.edu.eg

http://adjg.journals.ekb.eg

DOI: $10.21608 /$ adjg.2022.113137.1462

Pediatric Dentistry \& Orthodontics ( Pediatric Dentistry, Orthodontics)

\section{KEYWORDS}

Healthy, Special need, Children, General anesthesia, Treatment failure.

\begin{abstract}
Purpose: To compare outcomes of dental treatment under general anesthesia for special health care need and healthy children in a population in Saudi Arabia and to determine whether the patient medical history affects the failure rates of procedures performed under general anesthesia. Subjects and Methods: The records for children who had rehabilitation between 2017 and 2018 and attended the follow up visits for two years following their general anesthesia were examined. Data regarding restoration failures were statistically analyzed. Results: Special health care need children had significantly more extractions $(6.07 \pm 3.39)$ than healthy children $(4.92 \pm 3.00)$. For special health care need children less than 6 years of age, the composite strip crown showed $100 \%$ failure rate, whereas the preventive resin restoration showed the highest mean failure rate $(85.71 \pm 37.80)$ for healthy children. A higher significant difference was found between mean failure rate of stainless steel crowns $(21.28 \pm 22.92)$ among healthy children aged more than 6 years compared to special health care need children $(10.68 \pm 19.55)$. Conclusion: Treatment approaches used for special health care need and healthy children under general anesthesia differ significantly, with extraction being the most frequently performed procedure among special health care need children and stainless steel crown being the most commonly performed treatment in healthy children.
\end{abstract}

\section{INTRODUCTION}

The ability of pediatric dentists to treat children in a hospital setting and provide comprehensive dental care under general anesthesia (GA) is an imperative alternative ${ }^{(1)}$. The decision to treat children under GA is complex and takes into account the extent of treatment needed, the patient's behavior, medical history, and psychological health ${ }^{(1,2)}$. Despite the increased cost and risk of dental treatment under GA, which

1. Associate Professor, Pediatric Dentistry Department, Faculty of Dentistry, King Abdulaziz University, Jeddah, Saudi Arabia \& Assistant Professor, Department of Pedodontics and Oral Health, Faculty of Dental Medicine for Girls, Al-Azhar University, Cairo, Egypt.

* Corresponding author email: hkhodary@kau.edu.sa 
are exacerbated by longer wait times, it is considered effective since it enables the dentist to complete the treatment rather than defer it, and it eliminates the likely emotional distress associated with multiple visits or lengthy dental appointments ${ }^{(3)}$.

Children with special health care needs (SHCN) may be at an increased risk for oral diseases throughout their lives ${ }^{(4,5)}$, either because they have impaired motor and sensory coordination, limiting their ability to care for themselves and requiring general care from their parents or caregivers ${ }^{(4)}$, or because they have chronic diseases that predispose them to poor oral health outcomes due to sugary drugs, poor eating habits, and inadequate oral hygiene practices $^{(6)}$. In comparison to healthy children, $\mathrm{SHCN}$ children are more likely to exhibit elevated anxiety, decreased collaboration, and mood swings, frequent illness, numerous physician/hospital visits, family dynamics, and maternal depression, all of which indicate a lower degree of compliance with dental visits ${ }^{(7)}$. Numerous studies $(4,8,9)$ have indicated that children with SHCN have severe unmet dental needs. Thus, GA is a critical approach for dentists to provide comprehensive dental management for SHCN children without adding to their distress, potential dangers, or, most crucially, due to their inability to provide high-quality care in a chairside dental setting ${ }^{(10,11)}$.

In theory, GA may be utilized to deliver comprehensive, safe, and high-quality dental care to both healthy and SHCN patients under optimal settings, ensuring ideal outcomes ${ }^{(12)}$. Dental treatment under GA was compared between SHCN and uncooperative healthy children in several studies ${ }^{(10,13,14)}$. The bulk of these investigations found that individuals with SHCN required more extractions than those who were healthy ${ }^{(10,13-16)}$. Other studies indicated much lower frequencies of pulpotomies and stainless steel crowns in patients with $\mathrm{SHCN}^{(13,17)}$, while others reported significantly more restorative treatment $^{(15,16)}$. However, studies comparing dental treatment under GA provided to healthy and SHCN patients with respect to effect of patients' medical history on the treatment outcomes are limited. This is particularly evident in published studies from Arab nations, particularly Saudi Arabia, where minimal attention is placed on whether patient medical history has an effect on the result of dental treatment given under general anesthesia. Thus, the purpose of this study was to compare the patterns of dental treatment performed under GA on children with special health care needs and healthy children in a Saudi Arabian population and to determine whether the patient medical history has an effect on the failure rates of dental treatment performed under GA.

\section{MATERIALS AND METHODS}

This retrospective study was conducted as part of a larger project that began with children who received comprehensive dental care under GA between January 2017 and December 2018 at two tertiary government hospitals in Jeddah, Saudi Arabia: King Abdulaziz University Dental Hospital (KAUDH) and King Fahad Armed Forces Hospital (KFAFH). The centers are supported by the health ministry, and patients received treatment free of charge. The current study conducted a retrospective analysis of hospital records for all children who had their rehabilitation between January 2017 and December 2018 and attended the follow up visits for two years following their GA. By January 2021, a single pediatric dentist had located and evaluated these records. The study excluded children with missing or incomplete dental and/or medical records, as well as those who failed to attend the planned follow-up appointments after rehabilitation. Children were classified into two groups based on medical history provided by parents: healthy group and those with physical, mental, developmental, or sensory disabilities requiring medical treatment were assigned to the SHCN group. Children were then subdivided into two age groups $(<6$ years or $\geq 6$ years). The research approval was obtained by the Research Ethical Committee of the Faculty of Dentistry in King Abdulaziz University and the Local Research and Ethical Committee at KFAFH (062-15). 
Demographic data, medical history, the date of dental rehabilitation, types of treatments performed under GA, and information on restoration failures throughout the two-year period following GA rehabilitation were all acquired from the children' records. Failure was defined as a restoration that required replacement, was fractured or dislodged, or if the tooth required extraction due to infection, or was linked with pulpal or dento-alveolar infection or had recurring decay. For teeth treated with stainless steel crown (SSC), a failure was defined as an open margin, loose, or lost crown. Abscess, edema, fistula, pathologic mobility were all considered to be signs of treatment failure in teeth that had received pulp therapy. Teeth that were remaining roots or required extraction on the day of a follow-up visit after being treated previously under GA were also considered treatment failures. Absence of any of the aforementioned failure criteria throughout the recall visits, was considered as a treatment success.

SPSS statistics program (Statistical Package for the Social Sciences Inc., Chicago, IL, USA) version 20 was used to record and analyze all data. Quantitative variables were described using measures of central tendency (mean and standard deviation), while qualitative variables were described using frequencies and percentages. To determine the failure rates of all treatment modalities, a multiple response analysis was used. The differences between SHCN and healthy children were assessed utilizing unpaired t-tests. To find variations in qualitative characteristics between children medical history and failure rates of restorative procedures, the Chi-square test was performed. The significance level was set at 0.05 .

\section{RESULTS}

This retrospective study assessed the records of 634 children who received comprehensive dental treatment during January 2017 to December 2018. Out of the 634 patient records examined, 306 met the criteria of attending the scheduled follow-up visits for a period of two years after their rehabilitation. These comprised 85 (27.8\%) SHCN and 221 (72.2\%) healthy children. Most of the participants were males $(57.20 \%)$ and less than 6 years of age $(65.40 \%)$. Almost $44.8 \%$ of participants were from low-to-middle income family with both mothers and fathers having completed school $(56.90 \%$ $74.80 \%$ respectively), and having 5 or less siblings (71.60\%). In regards to parental occupation, a high proportion of participants had housewife mothers and military fathers $(77.50 \%$ and $62.10 \%$ respectively). The distribution of $\mathrm{SHCN}$ and healthy children according to their demographic characteristics was presented in Table 1.

Figure (1) Summarized percentages of children who had significant medical conditions among the SHCN group. The most common conditions were hematological disorders $(29.4 \%)$, respiratory disorders $(16.7 \%)$, mental retardation $(11 \%)$, congenital cardiac (10\%), immunological conditions (9\%), cerebral palsy $(8 \%)$ and renal disorders $(8 \%)$.

The mean number of dental treatments performed under GA was determined for the entire study sample was recoded. The most often performed procedure was extraction $(5.24 \pm 3.15)$, followed by composite restoration $(4.96 \pm 2.83)$ and SSC $(4.85 \pm 2.06)$. Additionally, the mean number of dental treatments performed under GA was determined for each group (SHCN and healthy children). Composite restorations were the most frequently performed procedures $(4.98 \pm 2.87)$ in healthy children, followed by SSC (4.97 \pm 2.02$)$ and extractions $(4.92 \pm 3.00)$, whereas extractions were the most frequently performed procedures $(6.07 \pm 3.39)$ in SHCN. Preventive resin restoration (PRR) was the least often performed procedure in children with SHCN and healthy children $(1.80 \pm 0.84$ and $1.40 \pm 0.52$, respectively). The SHCN children (6.07 \pm 3.39$)$ had significantly more extractions than healthy children (4.92 \pm 3.00$)$ (Figure 2) $(\mathrm{P} \leq 0.05)$. 
Table (1) Distribution of children with special health care need and healthy children according to demographic characteristics.

\begin{tabular}{|c|c|c|c|c|c|c|c|}
\hline \multirow[t]{2}{*}{ Demographic variables } & \multicolumn{2}{|c|}{$\begin{array}{c}\text { Total } \\
\mathbf{N}=\mathbf{3 0 6}\end{array}$} & \multicolumn{2}{|c|}{$\begin{array}{c}\text { SHCN Children } \\
\quad \mathbf{N}=85 \\
\end{array}$} & \multicolumn{2}{|c|}{$\begin{array}{c}\text { Healthy Children } \\
\mathbf{N}=\mathbf{2 2 1} \\
\end{array}$} & \multirow[t]{2}{*}{$P$-value } \\
\hline & $\mathbf{n}$ & $\%$ & $\mathbf{n}$ & $\%$ & n & $\%$ & \\
\hline \multicolumn{8}{|l|}{ Age of the patient } \\
\hline$<6$ years & 200 & 65.40 & 51 & 60.00 & 149 & 67.40 & \multirow{2}{*}{0.23} \\
\hline$\geq 6$ years & 106 & 34.60 & 34 & 40.00 & 72 & 32.60 & \\
\hline \multicolumn{8}{|l|}{ Gender } \\
\hline Male & 175 & 57.20 & 56 & 65.90 & 119 & 53.80 & \multirow{2}{*}{0.07} \\
\hline Female & 131 & 42.80 & 29 & 34.10 & 102 & 46.20 & \\
\hline \multicolumn{8}{|l|}{ Family income } \\
\hline Low & 64 & 20.90 & 23 & 27.10 & 41 & 18.60 & \multirow{4}{*}{0.19} \\
\hline Low to middle & 137 & 44.80 & 36 & 42.40 & 101 & 45.70 & \\
\hline Middle to high & 64 & 20.90 & 19 & 22.30 & 45 & 20.30 & \\
\hline High & 41 & 13.40 & 7 & 8.20 & 34 & 15.40 & \\
\hline \multicolumn{8}{|l|}{ Mother's education } \\
\hline Illiterate & 25 & 8.20 & 8 & 9.40 & 17 & 7.70 & \multirow{3}{*}{0.67} \\
\hline School & 174 & 56.90 & 45 & 53.00 & 129 & 58.40 & \\
\hline University and higher & 107 & 34.90 & 32 & 37.60 & 75 & 33.90 & \\
\hline \multicolumn{8}{|l|}{ Father's education } \\
\hline Illiterate & 9 & 3 & 3 & 3.50 & 6 & 2.70 & \multirow{3}{*}{0.92} \\
\hline School & 229 & 74.80 & 63 & 74.10 & 166 & 75.10 & \\
\hline University and higher & 68 & 22.20 & 19 & 22.40 & 49 & 22.20 & \\
\hline \multicolumn{8}{|l|}{ Mother's occupation } \\
\hline Housewife & 237 & 77.50 & 65 & 76.50 & 172 & 77.80 & \multirow{3}{*}{0.86} \\
\hline Government sector & 60 & 19.60 & 18 & 21.20 & 42 & 19.00 & \\
\hline Private sector & 9 & 2.90 & 2 & 2.30 & 7 & 3.20 & \\
\hline \multicolumn{8}{|l|}{ Father's occupation } \\
\hline Military & 190 & 62.10 & 43 & 50.60 & 147 & 66.50 & \multirow{4}{*}{0.05} \\
\hline Government sector & 41 & 13.40 & 15 & 17.60 & 26 & 11.80 & \\
\hline Private sector & 18 & 5.90 & 8 & 9.40 & 10 & 4.50 & \\
\hline Retired & 57 & 18.60 & 19 & 22.40 & 38 & 17.20 & \\
\hline \multicolumn{8}{|l|}{ Number of children in the family } \\
\hline 5 children or less & 219 & 71.60 & 58 & 68.20 & 161 & 73.20 & \multirow{3}{*}{0.62} \\
\hline 6 to 9 children & 72 & 23.50 & 23 & 27.10 & 49 & 21.80 & \\
\hline 10 children or more & 15 & 4.90 & 4 & 4.70 & 11 & 5.00 & \\
\hline
\end{tabular}

* Significant level is set at $p$ value $<0.05$ using Chi square test

N: Total number of subjects, $n$ : number of subjects in each category, SHCN: Special Health Care Need

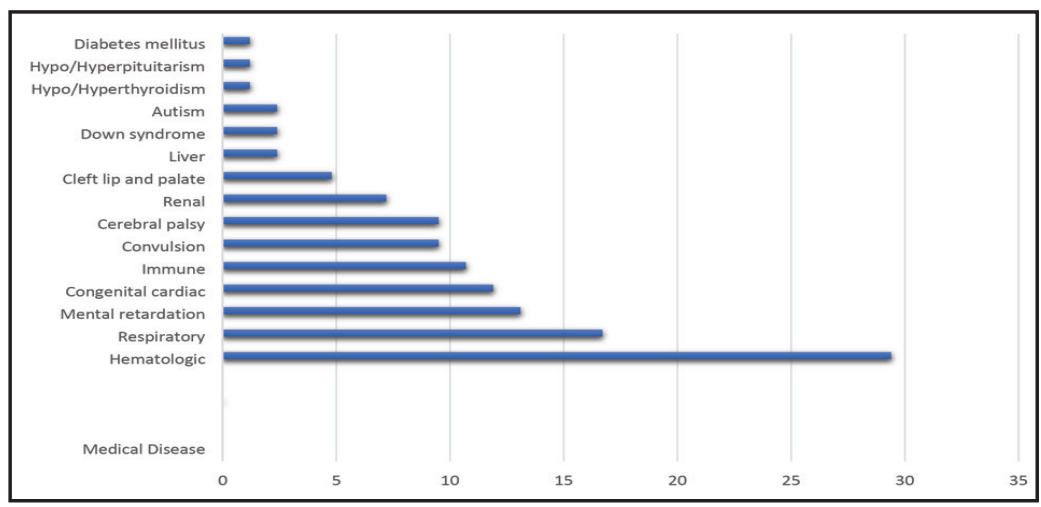

Figure (1) A bar chart showing the percentage distribution of children with special health care need according to medical history. 


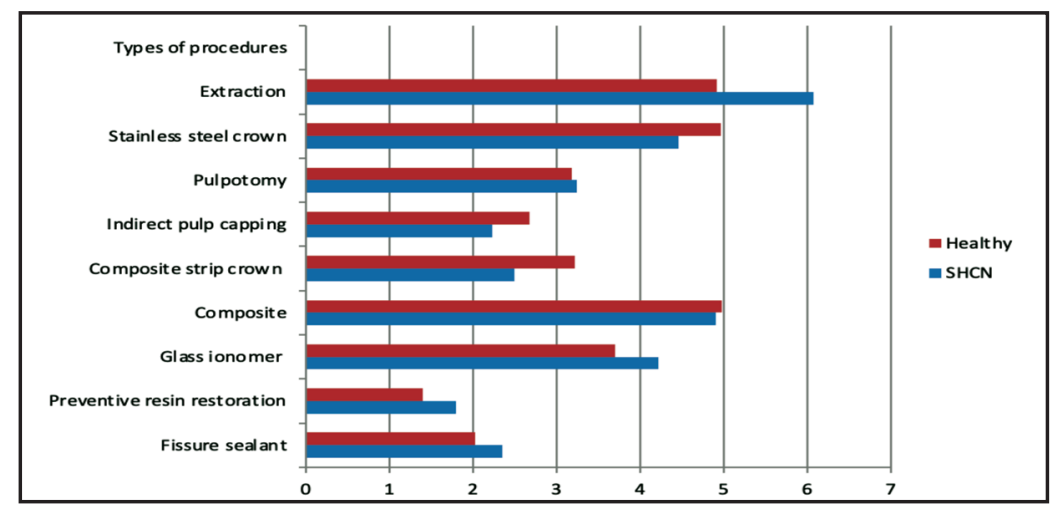

Figure (2) Mean numbers of procedures performed under general anesthesia among children with special health care needs and healthy children.

This study evaluated the mean failure rates of procedures conducted under GA by age group and medical history. For SHCN children less than 6 years of age; composite strip crown showed $100 \%$ failure rate $(100.0 \pm 0.0)$ whereas indirect pulp capping showed the least mean failure rate (26.19 \pm 38.32$)$. As for the healthy children, PRR showed the highest mean failure rate $(85.71 \pm 37.80)$ whereas SSC showed the least mean failure rate (24.05 \pm 25.76$)$. However, there were no statistically significant differences in failure rates for procedures performed based on medical history among children less 6 than years of age $(\mathrm{P}>0.05)$.
The mean failure rate of procedures performed under GA for children aged 6 years or more was also investigated based on medical history. Regarding the SHCN children, PRR showed the highest mean failure rate $(75.00 \pm 50.00)$ whereas SSC showed the least mean failure rate $(10.68 \pm 19.55)$. Among healthy children, PRR showed $100 \%$ failure rate $(100.0 \pm 0.0)$. A higher statistically significant difference was found between the mean failure rate of SSC among healthy children (21.28 \pm 22.92$)$ compared to SHCN children $(10.68 \pm 19.55)$ (Table 2 and 3$)(\mathrm{P} \leq 0.05)$.

Table (2) Mean failure rate of procedures performed under general anesthesia for $6<$ years old group according to medical history.

\begin{tabular}{|c|c|c|c|c|c|c|c|c|}
\hline \multirow{2}{*}{ Types of procedures } & \multirow{2}{*}{ Group } & \multirow{2}{*}{$\begin{array}{c}\text { Patients } \\
\mathbf{N}\end{array}$} & \multirow{2}{*}{$\begin{array}{c}\text { Procedures } \\
\mathbf{n}\end{array}$} & \multicolumn{4}{|c|}{ Procedures failure rate } & \multirow{2}{*}{$P$-value } \\
\hline & & & & Mean & \pm SD & 950 & CI & \\
\hline \multirow{2}{*}{ Fissure Sealant } & SHCN & 5 & 7 & 80.00 & 44.72 & 24.47 & 135.53 & \multirow{2}{*}{0.60} \\
\hline & Healthy & 16 & 27 & 67.19 & 47.19 & 42.04 & 92.33 & \\
\hline \multirow{2}{*}{$\begin{array}{l}\text { Preventive resin } \\
\text { restoration }\end{array}$} & SHCN & 1 & 2 & 50.00 & -0.00 & - & & \multirow{2}{*}{0.41} \\
\hline & Healthy & 7 & 10 & 85.71 & 37.80 & 50.76 & 120.67 & \\
\hline \multirow{2}{*}{ Glass ionomer } & SHCN & 9 & 41 & 75.78 & 29.36 & 53.21 & 98.35 & \multirow{2}{*}{0.36} \\
\hline & Healthy & 25 & 102 & 62.47 & 38.69 & 46.49 & 78.44 & \\
\hline \multirow{2}{*}{ Composite } & SHCN & 31 & 170 & 45.75 & 32.62 & 33.79 & 57.72 & \multirow{2}{*}{0.14} \\
\hline & Healthy & 134 & 673 & 55.66 & 33.98 & 49.85 & 61.47 & \\
\hline \multirow{2}{*}{ Composite strip crown } & SHCN & 5 & 17 & 100.00 & 0.00 & 100.00 & 100.00 & \multirow{2}{*}{0.23} \\
\hline & Healthy & 7 & 24 & 78.57 & 36.60 & 44.73 & 112.42 & \\
\hline \multirow{2}{*}{ Indirect pulp capping } & SHCN & 7 & 15 & 26.19 & 38.32 & -9.25 & 61.63 & \multirow{2}{*}{0.69} \\
\hline & Healthy & 32 & 92 & 32.45 & 37.46 & 18.94 & 45.95 & \\
\hline \multirow{2}{*}{ Pulpotomy } & SHCN & 32 & 118 & 33.16 & 36.87 & 19.87 & 46.45 & \multirow{2}{*}{0.42} \\
\hline & Healthy & 126 & 419 & 27.70 & 33.57 & 21.78 & 33.62 & \\
\hline \multirow{2}{*}{ Stainless steel crowns } & SHCN & 38 & 192 & 28.00 & 28.32 & 18.69 & 37.31 & \multirow{2}{*}{0.41} \\
\hline & Healthy & 153 & 758 & 24.05 & 25.76 & 19.93 & 28.16 & \\
\hline
\end{tabular}

* Significant level is set at $p$ value $<0.05$ using T- test

$N$ : Total number of subjects, $n$ : number of subjects in each category, SHCN: Special Health Care Need 
Table (3) Mean failure rate of procedures performed under general anesthesia for $\geq 6$ years old group according to medical history.

\begin{tabular}{|c|c|c|c|c|c|c|c|c|}
\hline \multirow{2}{*}{ Types of procedures } & \multirow{2}{*}{ Group } & \multirow{2}{*}{$\begin{array}{c}\text { Patients } \\
\mathbf{N}\end{array}$} & \multirow{2}{*}{$\begin{array}{c}\text { Procedures } \\
\text { n }\end{array}$} & \multicolumn{4}{|c|}{ Procedures failure rate } & \multirow{2}{*}{ P-value } \\
\hline & & & & Mean & \pm SD & $95^{\circ}$ & CI & \\
\hline \multirow{2}{*}{ Fissure Sealant } & $\mathrm{SHCN}^{9}$ & 12 & 33 & 59.72 & 44.64 & 31.36 & 88.09 & \multirow{2}{*}{0.06} \\
\hline & Healthy & 18 & 40 & 87.04 & 32.62 & 70.82 & 103.26 & \\
\hline \multirow{2}{*}{$\begin{array}{l}\text { Preventive resin } \\
\text { restoration }\end{array}$} & SHCN & 4 & 7 & 75.00 & 50.00 & -4.56 & 154.56 & \multirow{2}{*}{0.4} \\
\hline & Healthy & 3 & 4 & 100.00 & 0.00 & 100.00 & 100.00 & \\
\hline \multirow{2}{*}{ Glass ionomer } & SHCN & 9 & 35 & 34.55 & 40.01 & 3.80 & 65.30 & \multirow{2}{*}{0.74} \\
\hline & Healthy & 12 & 35 & 41.11 & 47.13 & 11.17 & 71.05 & \\
\hline \multirow{2}{*}{ Composite } & SHCN & 31 & 134 & 43.15 & 36.11 & 29.90 & 56.39 & \multirow{2}{*}{0.41} \\
\hline & Healthy & 50 & 244 & 49.58 & 32.34 & 40.39 & 58.77 & \\
\hline \multirow{2}{*}{ Composite strip crown } & SHCN & 2 & 3 & 50.00 & 70.71 & -58.31 & 69.31 & \multirow{2}{*}{0.42} \\
\hline & Healthy & 2 & 5 & 0.00 & 0.00 & - & & \\
\hline \multirow{2}{*}{ Indirect pulp capping } & SHCN & 6 & 14 & 25.00 & 41.83 & -18.90 & 68.90 & \multirow{2}{*}{0.88} \\
\hline & Healthy & 7 & 12 & 21.43 & 39.34 & -14.95 & 57.81 & \\
\hline \multirow{2}{*}{ Pulpotomy } & SHCN & 19 & 44 & 15.60 & 29.91 & 1.19 & 30.02 & \multirow{2}{*}{0.25} \\
\hline & Healthy & 47 & 131 & 26.99 & 37.74 & 15.91 & 38.07 & \\
\hline \multirow{2}{*}{ Stainless steel crowns } & SHCN & 31 & 116 & 10.68 & 19.55 & 3.51 & 17.85 & \multirow{2}{*}{$0.03 *$} \\
\hline & Healthy & 58 & 291 & 21.28 & 22.92 & 15.25 & 27.31 & \\
\hline
\end{tabular}

* Significant level is set at $p$ value $<0.05$ using T-test

$N$ : Total number of subjects, $n$ : number of subjects in each category, SHCN: Special Health Care Need

\section{DISCUSSION}

Given that oral health was identified as the most prevalent unmet health care need for $\mathrm{SHCN}^{(18)}$, and a prevalence of handicapping conditions of 36.7 per 1000 children in Jeddah, Saudi Arabia ${ }^{(19)}$, it seems critical to evaluate treatment provided to patients with special health care needs and explore the impact of their medical history on the outcomes and patterns of dental care provided. To expand the sample size in this study, children undergoing rehabilitation at two public hospitals in Jeddah were chosen. All dental treatments were performed by the same pediatric dentistry residents at both facilities on a rotational schedule during their training time and supervised by senior calibrated faculty members. This guaranteed that both institutions used comparable treatment protocols, procedures, and materials, avoiding procedural bias and permitting comparison of treatment outcomes for the goal of analyzing the association between patient medical history and restorative procedure outcomes.

Hematological and respiratory illnesses were the two main underlying problems in children with SHCN treated under GA in this study. This could be explained by the fact that these illnesses are becoming more prevalent in Saudi Arabia ${ }^{(20,21)}$. Children with SHCN accounted for approximately third of those treated with GA in the current trial. Other studies ${ }^{(10,22)}$ in Saudi Arabia revealed similar rates (23 percent and 27.6 percent respectively). Additionally, the majority of patients were healthy males under the age of six. This was comparable to the findings of a previous study ${ }^{(10)}$ in which boys were found less cooperative with dental treatment than girls. This was also confirmed another study ${ }^{(23)}$ who discovered that a disproportionate percentage 
of GA repeaters were boys, with an average age of 4.7 years at their second GA, implying that boys mature psychologically more slowly and lack the capacity to cope with dental treatment in the office.

In terms of the current findings, extraction was the most often performed procedure in children receiving GAin this study. When treatment modalities were compared between children with SHCN and healthy children, a statistically significant difference in the mean number of extractions was seen in the SHCN children. The findings were in agreement with preceding studies ${ }^{(15-17)}$. This could be because SHCN have a greater rate of carious lesions, either as a result of a lack of ability in maintaining oral hygiene or as a result of delayed access to dental care, at which point the teeth may have deteriorated significantly, lowering the prognosis for restoring such teeth. This is supported by data from Saudi Arabian studies indicating that young medically compromised patients had a higher mean (dmft) score when compared to healthy patients ${ }^{(18,24)}$. This was also validated by several international investigations ${ }^{(13,25,26)}$. Nonetheless, this argument should be carefully evaluated because our study did not assess failures of restorations based on decayed, missed, or filled scores, which may be considered a study limitation.

When the mean failure rate of different types of procedures performed under GA was compared in this study, SSC had significantly the lowest mean failure rates among both study groups. This is in agreement with other studies, concluding SSC as the most reliable restoration for treatment of caries lesions under GA. (27-30) Numerous studies (31-33) including those cited above, reported low failure rates of stainless steel crowns in the range of two to eight percent. Our results supported a recent study ${ }^{(30)}$ recommendation that SSC should be given strong attention in the treatment of primary molars under GA in children with severe caries in order to reduce retreatment. Composite strip crowns and PRR, on the other hand, were found to have the highest mean failure rates among SHCN and healthy children, respectively, but there was no statistical significance. This agrees with previous studies (27,32) reporting high rates of restoration failure and subsequent need for re-treatment when assessing outcomes for restorative procedures performed under GA. The reason for the high failure rate observed with these types of restorations could be due to low retention of sealants and flowable composite resin which, according to a prior study ${ }^{(34)}$, promotes flushing or breakdown of the restoration, resulting in recurrent caries. Another explanation could be attributed to a previous study ${ }^{(35)}$ findings, which showed that teeth with three or more decayed surfaces had a very low retention rate, especially in children with a high caries risk. This could explain the significant failure rate of composite strip crowns seen in our study.

When the study groups were further analyzed based on age and medical history, SSC mean failure rates among healthy children were shown to be significantly higher than SHCN children aged 6 years or more. SSC failures might be due to failures of associated pulpotomies where the mean failure rate of pulpotomies among healthy children was also higher compared to that in SHCN in the same age group, though the difference was not statistically significant. The reduced failure rate of SSC among SHCN was most likely due to dental discretion during GA, when this group of children was presented with higher caries activity or badly broken teeth, the decision was made to extract rather than restore to minimize any failure consequences after the GA. This was obvious in the current study by the higher number of extractions done among SHCN children compared to healthy children.

In this study, PRR placed in SHCN and healthy children aged 6 years or more, were found to have the highest failure rates but the differences were not statistically significant. This could be because individuals who require general anesthesia have a higher caries risk and are more likely to acquire new and recurrent caries ${ }^{(1)}$. This, in addition to high-calorie, fermentable-carbohydrate meals and oral hygiene constraints, could contribute to the 
failure rates of such preventive treatments. This was confirmed by one study reporting that $8.5 \%$ and $18.8 \%$ of the children required further GA at 6 and 12 months respectively due to recurrent caries ${ }^{(36)}$.

The study findings indicated that composite strip crowns in SHCN had the highest mean failure rate in the younger age group (less than 6 years). This was consistent with the findings of a prior research ${ }^{(37)}$, who reported that more than half of strip crowns placed in the full primary dentition under general anesthesia failed. Additionally, the study findings supported the results of a previous study ${ }^{(32)}$ where composite restorations and composite strip crowns had the highest failure rates. This could simply be because children who have a high caries risk and have been recommended for GA typically have higher subsequent caries rates ${ }^{(11)}$. Another possible explanation is that the lifetime of restorations is dependent on a variety of factors including material properties, operator ability, and patient characteristics ${ }^{(38)}$. SHCN patients may face additional problems, such as poor nutritional, oral, and behavioral habits that contribute to caries development and subsequent failure ${ }^{(39,40)}$. Additionally, this group of patients may have difficulty attending some recall visits following the $\mathrm{GA}^{(11)}$, which may contribute to the composite strip crowns' higher failure rate when compared to healthy patients. The study results also revealed that healthy children had a greater failure rate with PRR restorations than SHCN children, however there were no statistically significant differences, which could be related to patients' attitude following the GA. This highlights the importance of dentists collaborating on a health-promoting approach that could extend the duration of treatments for both SHCN and healthy children.

Every dental restoration that is dependent on the integrity of the dental enamel has a higher risk of failure than full coverage restorations ${ }^{(41,42)}$. However, while a failed restoration can be retreated in healthy children with minimal impact on their overall wellbeing, the condition may be distressing for a chronically ill child and may demand additional medical intervention ${ }^{(14)}$. Thus, proper treatment planning that takes into account the patient's underlying medical conditions, the outcomes of various treatment procedures, and the appropriate selection of restorative materials is critical to ensuring the delivery of high-quality dental services to SHCN and avoiding the need for repeat dental general anesthesia. In light of the above, it is necessary to acknowledge this study's shortcomings. The sample was unevenly distributed with 221 healthy children and 85 SHCN. The individual disabilities included in the SHCN group were not assessed separately, though similar sample characteristics were observed in an earlier study ${ }^{(37)}$. Although factors such as dexterity in maintaining adequate dental hygiene may affect the failure rate of restorations, these aspects were not included in this study. Due to the fact that subsequent caries beneath the restorations and asymptomatic periapical lesions cannot be diagnosed clinically, the failure rates may be underestimated. Future studies involving a large number of patients and institutions may aid researchers in gaining a better understanding of the factors affecting treatment outcomes. Additionally, because the findings are limited to Jeddah, future research in other Saudi locations are recommended to ensure that the findings are representative of Saudi children having GA for dental treatments.

\section{CONCLUSION}

The study findings indicate a considerable difference in the treatment approaches used for SHCN and healthy children under GA, with extraction being the most frequently performed procedure on SHCN children and SSC being the most frequently performed procedure on healthy children. Composite strip crowns and PRR restorations are less durable, whereas SSC restorations are more reliable. Restorative failures are common in both SHCN and healthy patients after comprehensive dental treatment under GA in both SHCN and healthy patients. The failure rate of restorations treated with GA is comparable in healthy and SHCN patients. 


\section{RECOMMENDATION}

Following GA rehabilitation, it is necessary to place a greater emphasis on oral health education and prevention initiatives. To provide a favorable outcome for patients with SHCN and healthy individuals treated under general anesthesia, the treatment approach must be well-formulated and executed. Parents and caregivers should be educated about the likelihood of restorative failure following their children's rehabilitations and encouraged to participate in dental disease prevention. All patients should have a specific maintenance strategy following their rehabilitation, designed in consultation with their guardians. This strategy may include reducing sugary snacks, applying fluoride, and adhering to a more regular recall schedule.

\section{CONFLICT OF INTEREST}

The author declares that there is no known competing financial interest or personal relationship that could have appeared to influence the work reported in this paper.

\section{FUNDING}

This research was not supported or funded by any agency.

\section{REFERENCES}

1. Oubenyahya H, Bouhabba N. General anesthesia in the management of early childhood caries: an overview. J Dent Anesth Pain Med. 2019; 19:313-22.

2. Emhardt JR, Yepes JF, Vinson LA, Jones JE, Emhardt JD, Kozlowski DC, Eckert GJ, Maupome G. Significant factors related to failed pediatric dental general anesthesia appointments at a hospital-based residency program. Pediatr Dent. 2017; 39:197-202.

3. Jamali Z, Najafpour E, Adhami ZE, Deljavan AS, Aminabadi NA, Shirazi S. Does the length of dental procedure influence children's behavior during and after treatment? A systematic review and critical appraisal. J Dent Res Dent Clin Dent. Prospects. 2018; 12: 68-76.

4. Chen CY, Chen YW, Tsai TP, Shih WY. Oral health status of children with special health care needs receiving dental treatment under general anesthesia at the dental clinic of Taipei Veterans General Hospital in Taiwan. J Chin Med Assoc. 2014; 77:198-202.

5. Craig MH, Scott JM, Slayton RL, Walker AL, Chi DL. Preventive dental care use for children with special health care needs in Washington's Access to Baby and Child Dentistry program. J Am Dent Assoc. 2019; 150:42-8.

6. Charles JM. Dental care in children with developmental disabilities: attention deficit disorder, intellectual disabilities, and autism. J Dent Child. 2010; 77:84-91.

7. Lerwick JL. Minimizing pediatric healthcare-induced anxiety and trauma. World J Clin Pediatr Dent.2016; 5:14350 .

8. Nelson LP, Getzin A, Graham D, Zhou J, Wagle EM, McQuiston J, McLaughlin S, Govind A, Sadof M, Huntington NL. Unmet dental needs and barriers to care for children with significant special health care needs. Pediatr Dent. 2011; 33:29-36.

9. Paschal AM, Wilroy JD, Hawley SR. Unmet needs for dental care in children with special health care needs. Prev Med Rep.2016; 3:62-7.

10. Al-Ogayyel S, Ali SA. Comparison of dental treatment performed under general anesthesia between healthy children and children with special health care needs in a hospital setting, Saudi Arabia. J Clin Exp Dent. 2018; 10:963-9.

11. Kasemkhun P, Smutkeeree A, Jirarattanasopha V. A retrospective comparison of dental treatment under general anesthesia versus non-pharmacological approach in patient with special health care needs. J Dent Sci. 2021; 12:1-6.

12. American Academy of Pediatric Dentistry. Behavior guidance for the pediatric dental patient. The Reference Manual of Pediatric Dentistry. Chicago, Ill.: AAPD; 2021: 306-24.

13. Sari ME, Ozmen B, Koyuturk AE, Tokay U. A retrospective comparison of dental treatment under general anesthesia on children with and without mental disabilities. Niger J Clin Pract. 2014; 17:361-5.

14. Ciftci V, Yazicioglu İ.A retrospective comparison of dental treatment under general anesthesia provided for uncooperative healthy patients and patients with special health care needs. J Clin Pediatr Dent. 2020; 44:196-201.

15. Chia-Ling Tsai B, Yi-Ling Tsai B, Yng-Tzer Lin B, Yai-Tin Lin B. A retrospective study of dental treatment under general anesthesia of children with or without a chronic illness and/or a disability. Chang Gung Med J. 2006; 29:412-8. 
16. Lee PY, Chou MY, Chen YL, Chen LP, Wang CJ, Huang WH. Comprehensive dental treatment under general anesthesia in healthy and disabled children. Chang Gung Med J. 2009; 32:636-42.

17. Baygin O, Tuzuner T, Kusgoz A, Yahyaoglu G, Yilmaz N, Aksoy S. Effects of medical and mental status on treatment modalities in patients treated under general anesthesia at the KTU Faculty of Dentistry in Trabzon, Turkey: A comparative retrospective study. J Pak Med Assoc. 2017; 67:305-7.

18. Alwattban RR, Alkhudhayr LS, Al-Haj Ali SN, Farah RF. Oral Health-Related Quality-of-Life According to Dental Caries Severity, Body Mass Index and Sociodemographic Indicators in Children with Special Health Care Needs. J Clin Med. 2021; 10:4811-23.

19. Abdullah Milaat, Tawfik Mohammad Ghabrah, Hussain Mohammad Salem Al-Bar, Baha Abudlrahman Abalkhail, Mohammahd Naji Kordy W. Population-based survey of childhood disability in Eastern Jeddah using the ten questions tool. Disabil Rehabil J. 2001; 23:199-203.

20. Al Tabbal AO, Al Humedi SS. Surveillance of the Most Prevalent Medical Diseases among Pediatric Age Groups and Evaluation of the Control Measures Used At Tabuk Hospitals, Saudi Arabia. Open Access Maced. J Med Sci. 2017; 5:182-7.

21. Owaidah T, Al Momen A, Alzahrani H,Almusa A, Alkasim F, Tarawah A, Al Nouno R, Al Batniji F, Alothman F, Alomari A, Abu-Herbish S. The prevalence of factor VIII and IX inhibitors among Saudi patients with hemophilia: Results from the Saudi national hemophilia screening program. Med. (Baltimore). 2017; 96:5456-63.

22. Al-Malik MI, Al-Sarheed MA. Comprehensive dental care of pediatric patients treated under general anesthesia in a hospital setting in Saudi Arabia. J Contemp Dent Pract. 2006; 7:79-88.

23. Sheller B, Williams BJ, Hays K, Mancl L. Reasons for repeat dental treatment under general anesthesia for the healthy child. Pediatr Dent. 2003; 25: 546-52.

24. Brown A. Caries prevalence and treatment needs of healthy and medically compromised children at a tertiary care institution in Saudi Arabia. East Mediterr. Health J. 2009; 15: 378-86.

25. Solanki N, Kumar A, Awasthi N, Kundu A, Mathur S, Bidhumadhav S. Assessment of oral status in pediatric patients with special health care needs receiving dental rehabilitation procedures under general anesthesia: a retro- spective analysis. J Contemp Dent Pract. 2016; 17:476-9.

26. Al-Maweri SA,Zimmer S. Oral health survey of 6-14-yearold children with disabilities attending special schools Yemen. J Clin Pediatr Dent. 2015; 39:272-6.

27. Mallineni SK, Yiu CK. A retrospective review of outcomes of dental treatment performed for special needs patients under general anesthesia: 2-year follow-up. Sci. World J. 2014: 748353

28. AlMotawah FN, Chandra Pani S, AlKharashi T, AlKhalaf S, AlKhathlan M, AlSultan F, AlMughirah A. Comparison of Survival Rates of Stainless-Steel Crowns Placed with and without Pulpotomy: A Two-Year Retrospective Study. Int J Dent. 2020: 8883189.

29. Liu F, Yang K, Wang P, Wu T, Li J, Guo Q. Trends, Characteristics, and Success Rates of Treatment for Severe Early Childhood Caries Under General Anesthesia: A Retrospective Study in Northwest China. J Clin Pediatr Dent. 2021; 45: 278-83.

30. Patel RV, Thikkurissy S, Schwartz SB, Gosnell ES, Sun Q, Cully JL. Preferential Use of Stainless Steel Crowns as a Strategy to Minimize Retreatment of Primary Molars under General Anesthesia. Pediatr Dent. 2021; 15: 43:24-7.

31. O'Sullivan EA, Curzon ME. The efficacy of comprehensive dental care for children under general anesthesia. Br Dent J. 1991; 171:56-8.

32. Tate AR, Ng MW, Needleman HL, Acs G. Failure rates of restorative procedures following dental rehabilitation under general anesthesia. Pediatr Dent. 2002; 24: 69-71.

33. Al-Eheideb A, Herman N. Outcomes of dental procedures performed on children under general anesthesia. J Clin Pediatr Dent. 2004; 27:181-3.

34. Lekic PC, Deng D, Brothwell D. Clinical evaluation of sealants and preventive resin restorations in a group of environmentally homogeneous children. Dent Child. 2006; 73:15-9.

35. Ram D, Fuks AB. Clinical performance of resin-bonded composite strip crowns in primary incisors: a retrospective study. Int J Paediatr Dent. 2006; 16: 49-54.

36. Jiang H, Shen L, Qin D, He S, Wang J. Effects of dental general anaesthesia treatment on early childhood caries: a prospective cohort study in China. BMJ open. 2019; 9: 028931 .

37. Ng MW, Tate AR, Needleman HL, Acs G. The influence of medical history on restorative procedure failure rates following dental rehabilitation. Pediatr Dent. 2001; 23:487-90. 
38. Askar H, Krois J, Göstemeyer G, Schwendicke F. Secondary caries risk of different adhesive strategies and restorative materials in permanent teeth: Systematic review and network meta-analysis. J Dent. 2021; 104:103541.

39. Devalia U, Hood K. Medical Conditions in Paediatric Dentistry. In Pediatric Dentistry for the General Dental Practitioner 2021; 145-85.

40. Devinsky O, Boyce D, Robbins M, Pressler M. Dental health in persons with disability. Epilepsy Behav. 2020; 110:107174.

41. Harrison MG, Roberts GJ. Comprehensive dental treatment of healthy and chronically sick children under intubation general anaesthesia during a 5-year period. Br Dent J. 1998; 184 :503-6.

42. Randall RC. Preformed metal crowns for primary and permanent molar teeth: review of the literature. Pediatr Dent. 2002; 24: 489-500. 